\title{
Acuerdos comerciales profundos y cadenas globales de valor: el caso de Chile, Colombia y Brasil
}

\author{
Deep Trade Agreements and Global Value \\ Chains: The Case of Chile, Colombia and Brazil
}

\section{Acordos Comerciais Profundos e Cadeias Globais de Valor: o caso do Chile, Colômbia e Brasil}

Julieta Zelicovich ${ }^{*}$

Fecha de recepción: 27 diciembre 2018

Fecha de aceptación: 9 de abril de 2019

Cómo citar este artículo/ To reference this article / Comment citer cet article / Para citar este artigo:

Zelicovich, J. (2019). Acuerdos comerciales profundos y cadenas globales de valor: el caso de Chile, Colombia y Brasil. Apuntes del CENES, 38(68), 81 - 112. https://doi.org/10.19053/01203053.v38.n68.2019.8808

* Ph.D. Relaciones internacionales. Consejo Nacional de Investigaciones Científicas y Técnicas, CONICET, Argentina. julieta.zelicovich@fcpolit.unr.edu.ar (3ttp://orcid.org/0000-0002-8524-9002 


\section{Resumen}

El trabajo analiza la influencia de la participación de un país dentro de las cadenas globales de valor en la adopción de acuerdos comerciales profundos. Para ello se combina el análisis estadístico con el estudio de caso para tres países latinoamericanos: Chile, Colombia y Brasil. Se sostiene que una participación elevada en los encadenamientos productivos globales puede resultar suficiente para explicar la firma de tales acuerdos, pero que no constituye un elemento necesario para la misma. Por el contrario, las variables político-ideológicas, como las orientaciones del modelo de desarrollo o la estrategia de inserción internacional, han sido tan o más importantes que la participación en las cadenas globales de valor para explicar el tipo de compromisos en materia de integración regional.

Palabras clave: comercio internacional, acuerdos sobre mercancías, globalización, integración económica, cadenas globales de valor.

Clasificación JEL: F13, F14, F15, F50, F55. 


\begin{abstract}
The paper analyzes the influence of a country's participation within the global value chains in the adoption of deep trade agreements. To do this, the paper combines statistical analysis with the case study of three Latin American countries: Chile, Colombia and Brazil. It is argued that a high participation in global value chains may be a sufficient cause to explain the signature of such agreements, but that it does not constitute a necessary cause for it. On the contrary, other political-ideological variables, such as the orientations of the development model or the strategy of international insertion have been equally or even more important than the participation in the global value chains to explain these type of commitments in regional integration agreements.
\end{abstract}

Keywords: international trade, commodity agreements, globalization, economic integration, global value chains. 


\section{Resumo}

O artigo analisa a influência da participação de um país nas cadeias globais de valor na adoção de acordos comerciais profundos. Para fazer isso, a análise estatística é combinada com o estudo de caso de três países latino-americanos: Chile, Colômbia e Brasil. Argumenta-se que uma alta participação nas cadeias produtivas globais pode ser suficiente para explicar a assinatura de tais acordos, mas que não constitui um elemento necessário para isso. Pelo contrário, as variáveis político-ideológicas, como as orientações do modelo de desenvolvimento ou a estratégia de inserção internacional, têm sido tão ou mais importantes do que a participação nas cadeias de valor globais para explicar o tipo de compromissos em termos de integração regional.

Palavras-chave: comércio internacional, acordos de commodities, globalização, integração econômica, cadeias de valor globais. 


\section{INTRODUCCIÓN}

¿Influye la participación de un país dentro de las cadenas globales de valor en la adopción de acuerdos comerciales profundos? Ambos fenómenos, el de los acuerdos comerciales regionales (ACR) "profundos" y la articulación del comercio en cadenas globales de valor (CGV), se han incrementado de manera exponencial desde comienzos del siglo XXI, sin embargo ison dos tendencias que se encuentran vinculadas?

Dentro de los estudios de las relaciones internacionales y de la economía política internacional es ampliamente aceptado que el incremento en los acuerdos preferenciales se relaciona, en gran medida, con lo que Baldwin ha denominado brecha entre "el comercio del siglo XXI y las reglas del siglo XX" (Baldwin, 2011, p.8). Según este autor, la articulación de la producción y consumo en torno a las CGV habría generado una serie de demandas particulares sobre el nexo "comercio-servicios e inversiones" a las que los Estados habrían respondido con reformas unilaterales, tratados bilaterales de inversión y, fundamentalmente, acuerdos de integración profundos, fenómeno denominado "regionalismo del siglo XXI". De ser así, podría observarse un cambio en las políticas comerciales y económicas exteriores de los países a medida que estos incrementen su participación en las CGV, y la firma de ACR profundos resultaría un indicador de la referida transformación.

En la literatura se ha argumentado que los cambios en el tipo de comercio que involucra la participación en las CGV modifican los efectos de los instrumentos de política comercial y, con ello, alteran las preferencias de los policy-makers respecto de la aplicación de reformas unilaterales, la búsqueda de acuerdos preferenciales o bien multilaterales (Antrás \& Staiger, 2012; Blanchard, Bown \& Johnson, 2016). Se han desarrollado también trabajos donde se manifiesta el doble sentido del vínculo aquí estudiado: las CGV como disparadores de la firma de acuerdos, a la vez que la firma de acuerdos profundos como facilitadores del desarrollo de encadenamientos productivos (Orefice 
\& Rocha, 2011; López, 2012; Ruta, 2017; Laget, Osnago, Rocha \& Ruta, 2018). Asimismo se puede identificar una vasta literatura respecto a la manera en la que la inserción en las cadenas de valor repercute en el avance de la economía de los países desarrollados y en desarrollo (Baldwin, 2012; Organización Mundial del Comercio [OMC], 2014; Prochnik, 2010; Duran \& Zaclicever, 2013).

En este trabajo nos proponemos testear algunas de las características específicas de la relación entre CGV y ACR profundos. En la primera parte analizamos si una participación elevada en las CGV ha ido emparentada a la firma de ACR profundos en los países miembros de la Organización para la Cooperación y el Desarrollo Económico (OCDE) y algunas economías en desarrollo para las que se dispone de datos de manera sistematizada. Observamos que una mayor participación en $\mathrm{CGV}$ suele ir acompañada por una propensión a adoptar políticas propias del "regionalismo del siglo XXI", a la vez que se identifican numerosos casos de países con baja participación en las CGV pero con compromisos de integración profundos. Estos últimos resultan casos disonantes con las explicaciones del mainstream. Conforme a los datos relevados, se concluye que una participación elevada en las CGV puede resultar un elemento suficiente para explicar la firma de ACR profundos, pero no es un elemento necesario para la misma. En la segunda parte intentamos indagar en las causas de algunas de las variaciones que se observan en este vínculo, a partir del estudio de tres casos de países latinoamericanos, a saber: Colombia, Chile, y Brasil. En estos, las variables político-ideológicas, como las orientaciones del modelo de desarrollo o la estrategia de inserción internacional, han sido tan o más importantes que la participación en las CGV para explicar los distintos grados de intervención en los acuerdos mencionados.

Para el desarrollo de las hipótesis se adoptó un diseño de investigación mixto. En la primera parte se recurrió a una metodología cuantitativa, apoyada en el análisis descriptivo y estadístico de dos bases de datos: por un lado, la elaborada por la iniciativa de la OECD y de la Organización Mundial de Comercio (OMC) conocida como Trade in Value-Added (TiVA), que permitió conocer el grado de participación en las CGV de 60 países desarrollados y en desarrollo; y por otro, la de Dür, Baccini, y Elsig (2014), a partir de la cual fue posible establecer el nivel de profundidad de los ACR firmados por tales países. Los alcances temporales de dichas bases de datos limitaron el recorte temporal del análisis, centrándose esta primera parte en la comparación del año 1995 con 2011. Con este enfoque se pretendió inicialmente dar cuenta del grado de correlación de la firma de acuerdos comerciales profundos en función de la participación de los países en las CGV.

Para la segunda parte, en la que se indagaron los mecanismos causales de 
dicha relación, se implementó una metodología de corte cualitativa, a partir del análisis de fuentes documentales y fuentes secundarias vinculadas con las políticas comerciales externas de los países latinoamericanos elegidos. La selección de estos casos se fundamenta en la heterogeneidad de conductas que plantean, aun perteneciendo a un espacio regional común. Se basa además en un criterio de factibilidad, a raíz de la mayor información disponible de estos países en relación con el resto de la región. El recorte temporal, por su parte, se centra en los tres primeros lustros del siglo XXI, período en el que se acentúa el fenómeno de las CGV como paradigma productivo y en el que se presentan con mayor intensidad los cambios en las políticas comerciales y en los acuerdos de integración bajo estudio. Con esta segunda parte del estudio se busca complementar la primera parte de la investigación y controlar los problemas que las conclusiones provisionales de misma pudieran presentar en razón de las alternativas señaladas en la literatura respecto de la secuencia temporal entre la firma de los ACR profundos como antecedente o consecuente de la participación del país en las CGV, o bien de la intervención de otras variables (la remoción de otro tipo de barreras no contempladas en los ACR profundos) en la participación dentro de las CGV.

La relevancia del trabajo viene dada tanto por su debate con la literatura existente, como por sus implicaciones para las políticas públicas. Se busca a través del testeo de estas hipótesis la revisión de una interpretación extendida en el mainstream respecto de las CGV como impulsoras de los ACR profundos. El énfasis en los países sudamericanos, luego, contribuye a la reflexión respecto de las políticas hacia los ACR en contextos específicos, algo menos usual en la literatura dedicada al tópico en cuestión.

El artículo se organiza en cuatro apartados: en el primero exponemos distintas consideraciones conceptuales referidas a las CGV, los ACR profundos y su incidencia teórica sobre los procesos de formulación de políticas. En el segundo apartado examinamos cómo se ha dado esta relación de ACR profundos y CGV en los países que integran la base de datos TiVA. En el tercer apartado nos centramos en el comportamiento de los casos latinoamericanos. Finalmente, en el cuarto apartado se exponen las conclusiones de la investigación.

\section{LAS CADENAS GLOBALES DE VALOR Y SU VINCULACIÓN CON LOS ACUERDOS COMER- CIALES PROFUNDOS}

Bianchi y Szpack definen las cadenas globales de valor como "la secuencia de unidades productivas [ubicadas en diferentes países] que realizan actividades tangibles e intangibles, agregando valor en pos de la creación de un bien o servicio, y que abarcan desde su concepción, hasta la entrega final a los consumidores" (Bianchi \& Szpak 2015, p. 10). 
Esta forma de organizar la producción y el consumo parte de las deslocalizaciones productivas de la década del 70, tomando un impulso notable desde comienzos de los 90 y convirtiéndose en un fenómeno distintivo y singular de la economía internacional en la primera década del siglo XXI. La lógica detrás de las CGV es la búsqueda de eficiencia económica y de ventajas competitivas basadas en los costos de transacción, por parte de las empresas transnacionales (Bathia, 2013).

El concepto tiene su origen en el desarrollo de la teoría del sistema-mundo, en la obra de Hopkins y Wallerstein (1977), pero debe su popularización al auge de las ideas neoliberales en los años 90 y, en particular, al trabajo de Gereffi (Fernández \& Trevignani, 2015). Con el término de CGV no solo se describe una manera de ordenar la producción, sino que implica un marco analítico más amplio en el que se reconoce una dimensión internacional en el análisis; se visibilizan las relaciones de poder entre las empresas; se pondera la coordinación de una cadena como ventaja competitiva y se considera al aprendizaje organizativo como mecanismo de ascenso (Gereffi, 2001).

Según Baldwin (2011, 2012), la globalización de la economía se produjo en una serie de etapas graduales, en las cuales las diferentes innovaciones en materia de transporte, comunicaciones y tecnología hicieron posible la deslocalización de la producción y el consumo. Una primera etapa tuvo lugar comenzando con la reducción de los costos del transporte y permitió el aprovechamiento de economías de escala, aunque con algunas limitaciones propias de los requisitos de coordinación de la producción. La segunda etapa, a partir de la revolución en las tecnologías de la información y de la comunicación (TIC), permitió superar ese escollo, llevando la internacionalización de la producción y consumo a un nuevo estadio, materializado en la extensión y expansión de las CGV.

Esta profundización y extensión de la globalización generó una demanda por parte de las empresas para la provisión de nuevos tipos de disciplinas relacionadas con el comercio y la inversión, no previstas durante las primeras etapas ${ }^{1}$. En particular, pasó a requerirse con mayor intensidad la libre circulación de bienes, servicios, capital y personas, y el reaseguro de determinada infraestructura tangible e intangible que permita la coordinación de la producción a través de distintos espacios territoriales. Estas necesidades se conjugaron en dos imperativos centrales, "conectar las fábricas" y "hacer negocios afuera", frente a los cuales los Estados habrían respondido con tres tipos de reformas: reformas

1 Hasta ese momento, la liberalización del comercio llevada adelante en el seno del Acuerdo General de Aranceles y Comercio (GATT, por sus siglas en inglés) había acompañado este proceso de internacionalización de las empresas a través de una baja generalizada de los aranceles y la regulación de algunas pautas de conducta en el seno del comercio multilateral (Hoekman \& Kostecki, 2009). La nueva etapa de expansión, no obstante, requeriría de otras normas que no resultaban provistas por el sistema multilateral de comercio. 
unilaterales, tratados bilaterales de inversión y ACR profundos.

Los acuerdos profundos son aquellos que conjugan normas $\mathrm{OMC}+$, es decir, normas que ahondan en los compromisos ya existentes dentro del régimen multilateral, y normas OMCx, las cuales abordan temas no tratados anteriormente de manera directa en la OMC (OMC, 2011). Dentro de la agenda de ACR profundos se destacan cuatro áreas: política de competencia, movimientos de capital, propiedad intelectual e inversiones. Adicionalmente se incorporaron también cuestiones relativas a la armonización de reglamentaciones técnicas, la facilitación del comercio, el comercio electrónico, el medio ambiente y las políticas laborales.

Este proceso de reformas asociado a las CGV habría tenido lugar en los países desarrollados primero, y en algunos países en desarrollo después, destacándose el rol del sudeste asiático, pero, para Baldwin (2011), podría ser considerado un fenómeno global. A comienzos de la década del 2010 se identificaban tres grandes núcleos en torno a los cuales se articulaban las CGV de países desarrollados y en desarrollo: la "fabrica Estados Unidos", la "fábrica Europa" y la "fábrica Asia", siendo esas las tres regiones con mayor densidad de vinculaciones en el marco de los encadenamientos productivos globales.
Según una interpretación bastante extendida en la literatura respecto de la relación directa y positiva entre participación en CGV y desarrollo (Gereffi, Humphrey, Kaplinsky \& Sturgeon, 2001),

los gobiernos de las principales potencias económicas asumieron el papel de promotores del cambio, y fundamentalmente de su propio sector empresarial transnacional, en la búsqueda de mantener o asumir el liderazgo de las nuevas formas de competencia que se avecinaban. Del mismo modo, las principales instituciones multilaterales (FMI, Banco Mundial) se convirtieron no sólo en destacadas promotoras sino en inductoras de los cambios. (Basave, 2007, p. 202)

Las reformas se presentaban como una vía rápida para la industrialización y el crecimiento en los países emergentes, en tanto que en pocos casos se señalaban los límites de estas políticas (Dalle, Fossati \& Lavopa, 2013). A través de la reducción de los costos, los gobiernos proponían integrar las empresas nacionales en las cadenas o mejorar su posición en estas (Nicita, Ognivtsev \& Shirotori, 2013).

Para los enfoques desarrollistas y neoschumpetereanos, en cambio, los beneficios de la participación no revestían una linealidad semejante, sino que se limitan en función de las posibilidades 
de upgrading $^{2}$ propias de cada estructura de gobernanza de las cadenas (Gereffi, 2001). Ello además depende de las estructuras productivas y de la elasticidad precio de las exportaciones. En parte de la literatura se resalta también el rol de las políticas industriales en la consecución de las metas de desarrollo asociadas a la participación en CGV (Dalle et al., 2013). Se sostiene que

inserción a las CGV y desarrollo económico no son sinónimos: si bien una mayor integración a la las cadenas de valor puede generar beneficios a largo plazo, la evidencia indica que relativamente pocos países en desarrollo han logrado incrementar su porción de valor agregado doméstico y construir nuevas habilidades y capacidades productivas a través de este medio. (Dalle et al., 2013, p. 10)

Cuatro riesgos se presentan en la participación en las CGV: la vulnerabilidad a los ciclos comerciales mundiales, la desigualdad de ingresos, el traslado de empresas y la (in)adecuación de la fuerza de trabajo para asumir nuevas tareas (OMC, 2014). Por su parte, las lecturas desde la teoría del sistema mundo plantean que las CGV reproducen las relaciones centro-periferia y la dominación jerárquica inherente al sistema capitalista, como un todo (Fernández \& Trevignani, 2015). Las CGV tienden a favorecer a los países grandes, con amplia demanda doméstica, mejor infraestructura y empresas grandes que tengan capacidad de ascender en los eslabonamientos productivos (Bathia, 2013). De manera que en la literatura existe evidencia respecto del impacto negativo que las CGV pueden tener en la macroeconomía de países en desarrollo, especialmente sobre el empleo, puesto que los beneficios de la participación en dichas cadenas quedan concentrados en una elite pequeña de empresas globalmente integradas (Rodrik, 2018).

Debe notarse que la articulación entre participación en CGV y reformas políticas no ha resultado automática, sino que el intercambio entre "demanda" y "oferta" de este tipo de normativas y acuerdos (reflejado en la relación Estado-empresas) ha dependido de la estructura decisoria de cada país. Siguiendo los diferentes enfoques que analizan la política externa (Breuning, 2007), un cambio en las políticas públicas, del estilo sugerido por Baldwin, tendría lugar a partir de una modificación en alguna de las instancias del proceso de toma de decisiones. Esto podría deberse a la introducción de un nuevo "problema" que dispara la decisión (y aquí cabe preguntarse quién posiciona el problema). Alternativamente, podría derivar de una modificación en la percepción de los condicionantes internos o externos por parte del grupo decisorio o de la

2 Conforme a Gereffi, "el ascenso industrial implica cambiar las cadenas productivas de actividades intensivas en mano de obra a actividades intensivas en capital y habilidades, que conlleven aprendizaje organizativo para mejorar la posición de las empresas o de las naciones en el comercio internacional y en las redes de producción" (Gereffi, 2001, p. 28). 
"última unidad decisoria" (Hermann, 2001). Asimismo, también podría ocurrir debido a cambios en los canales de comunicación entre empresas y gobierno, o dentro de las prácticas de las burocracias.

Entre la primera de estas alternativas teóricas puede considerarse la presencia de las empresas multinacionales tanto nacionales como extranjeras como el principal actor que demanda al Estado estas reformas o bien, los gobiernos de las casas matrices de tales empresas, que pueden ser quienes canalicen esas demandas posicionando el problema desde el exterior (Strange, 1996; Gilpin, 2001; Baldwin, 2011; Osgood, 2018). Esta sería la interpretación del mainstream, conforme a la cual resulte esperable hallar una mayor profundidad de los ACR celebrados, en relación con el nivel de participación en las CGV.

Para la segunda alternativa debe tomarse en consideración el rol de los modelos o estrategias de desarrollo ${ }^{3}$ como lente a través de la cual se perciben y articulan las amenazas y oportunidades externas y domésticas que fundamentan los procesos decisorios. Algunas variables en esa línea de interpretación han sido consideradas en Antrás y Staiger, para quienes "the underlying problem for a trade agreement to solve in the presence of offshoring varies with the preferen- ces of member governments" (2012, p. 3143); así como en Bathia (2013).

Para la tercera teoría resulta fundamental contemplar la continuidad y el cambio en los partidos a cargo de gobierno o bien las variaciones de régimen político y su correspondiente realineación de las coaliciones de apoyo (Lasagna, 1995; Moravcsik, 1997). Estos dos modelos teóricos contribuirán a explicar los casos que se desvían de la tendencia general, conforme se explica en el apartado tercero de la investigación.

En los tres casos, una vez iniciado el proceso de reformas, los reacomodos que el mismo genera dentro del Estado y en sus vínculos externos, reproducen y retroalimentan la decisión, avanzando de forma incremental en la firma de nuevos ACR profundos y tratados bilaterales de inversión. Por un lado, los sectores que compiten con las importaciones ven disminuido su poder de ejercer influencia sobre los gobiernos (Baldwin, 2011). Por otro lado, terceros Estados pueden considerar la firma de un acuerdo como una amenaza a su posición estratégica y demandar entonces la firma de nuevos tratados. En Mansfield y Milner (1999) se reconoce que ciertas inquietudes basadas en la "interacción estratégica" han estado detrás de los regionalismos posteriores a la Segunda Guerra Mundial. De acuerdo con tal interpretación, los países pueden celebrar ACR no solo

3 "El modelo de desarrollo refiere a la manera en la que se articulan la política y la economía, entre el Estado y el mercado en un contexto histórico determinado. A cada modelo le corresponde un modo de producción, de distribución de la riqueza y una estrategia de inserción internacional” (Actis, Lorenzini \& Zelicovich, 2015, p. 16). 
por el hecho de que existe un interés económico entre sí, sino también como reacción "estratégica" a la conducta de otros Estados que establecieron ACR previamente (sea para disminuir la erosión de ventajas o competitividad o sea para igualar los beneficios percibidos por estos últimos), o como acción "estratégica" para ganar poder de mercado y poder de negociación (esto especialmente en el caso de los países en desarrollo).

\section{LAS CADENAS GLOBALES DE VALOR Y LOS ACUERDOS COMERCIALES PROFUNDOS EN EL ESCENARIO GLOBAL RECIENTE}

Al poco tiempo de haberse incrementado la intensidad de las CGV, comenzaron a presentarse distintos métodos e indicadores que buscaban mejorar la medición del comercio, evitando el doble cómputo de los intercambios comerciales y precisando la magnitud y carácter de la participación de cada economía en este tipo de producción y comercio. La base de datos "Trade in Value Added" se encuentra entre esos trabajos.

Del conjunto de los indicadores que esta contiene, en esta investigación nos centramos en tres: la participación de insumos importados sobre el total de las exportaciones del país, es decir, el VA "extranjero" o bien la participación "hacia atrás" — regresiva - en la cadena; en segundo lugar, la participación de insumos producidos en el país que se incluye en las exportaciones de otros países (exportaciones indirectas), es decir, el VA "doméstico", conocido como la participación "hacia adelante" - progresiva - en las CGV. La suma de ambos constituye el índice de participación en las CGV (GVC Index), el cual es expresado como porcentaje de las exportaciones totales y permite conocer el grado de integración de un país en la economía mundial.

En cuanto a los acuerdos comerciales, utilizamos la base creada por Dür et al. (2014), "Design of Trade Agreements" (DESTA), la cual reúne 790 acuerdos con información sobre sus características de diseño, para el período 19472010. En dicha base nos enfocamos particularmente en el índice de profundidad, el cual resulta consistente con las definiciones de "ACR profundos" presentadas en el apartado anterior. Este índice clasifica entre 1 y 7 a los acuerdos comerciales, según cumplan con las siguientes características: eliminación de los aranceles, compromisos sustanciales - que impliquen acciones concretas en las políticas - en comercio de servicios, en inversiones, en normas de contratación pública, en políticas de 
competencia y en los derechos de propiedad intelectual. Una mayor puntuación implica acuerdos más profundos.

El análisis de la vinculación entre los ACR y CGV se hizo a partir de la comparación de los valores de estas dos bases de datos, para un total de 604 casos considerando dos años de referencia: 1995 y 2011. Para cada país obtuvimos un par de datos que se refieren (según el caso) al tipo y nivel de participación en las CGV, y a la mayor profundidad de compromisos alcanzada en al menos uno de sus acuerdos comerciales, en los dos momentos seleccionados.

Los resultados pueden apreciarse en las siguientes figuras:

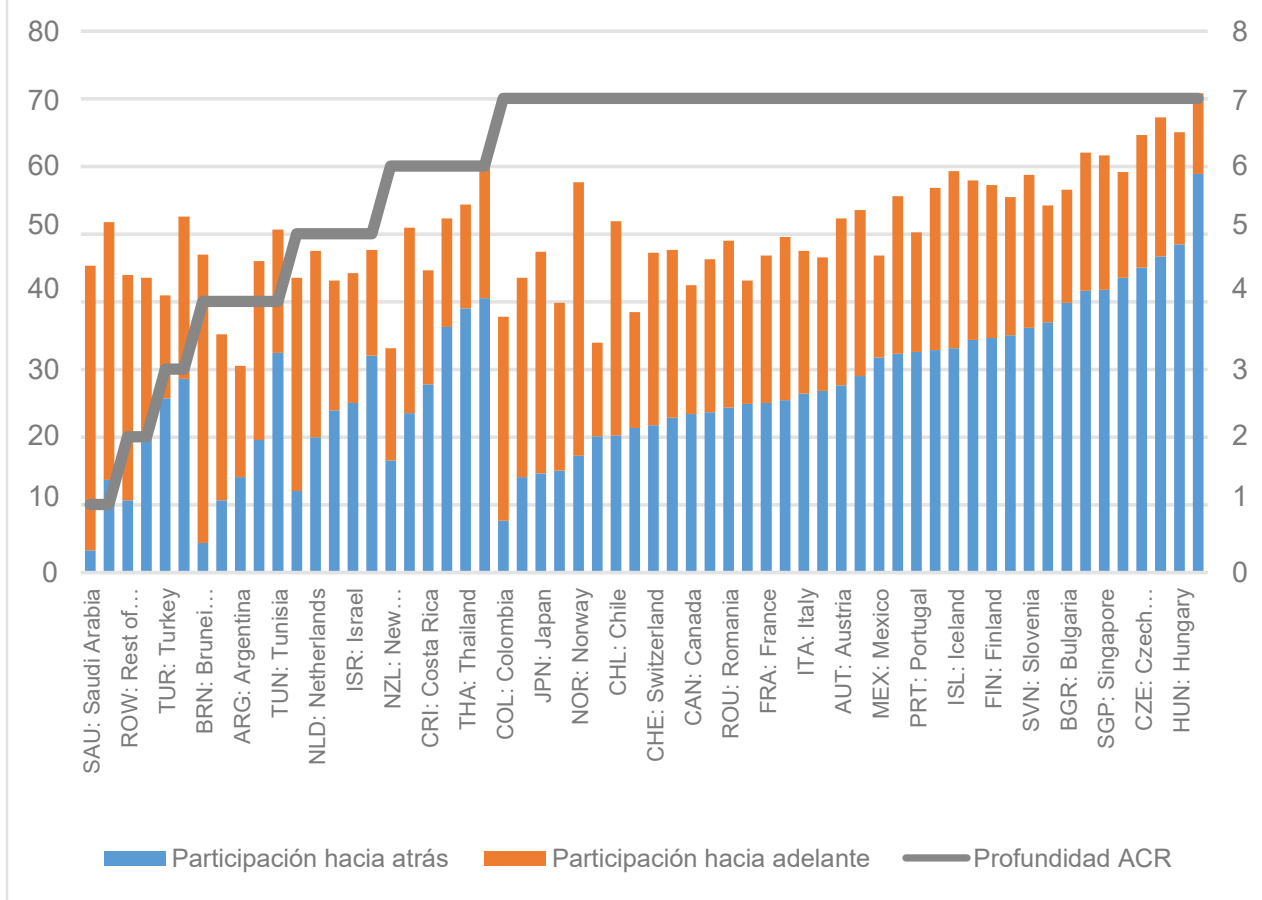

Figura1. Participación en las CGV y profundidad de los ACR 2011. Participación en las CGV (eje izquierdo)

Proundidad de los ACR (eje derecho)

4 Fueron excluidos de la muestra tres casos de la base de OECD, para los que no se contaba con valores de referencia en Dür et al. (2014). El promedio del "resto del mundo" es tomado como un caso dentro de la muestra. 


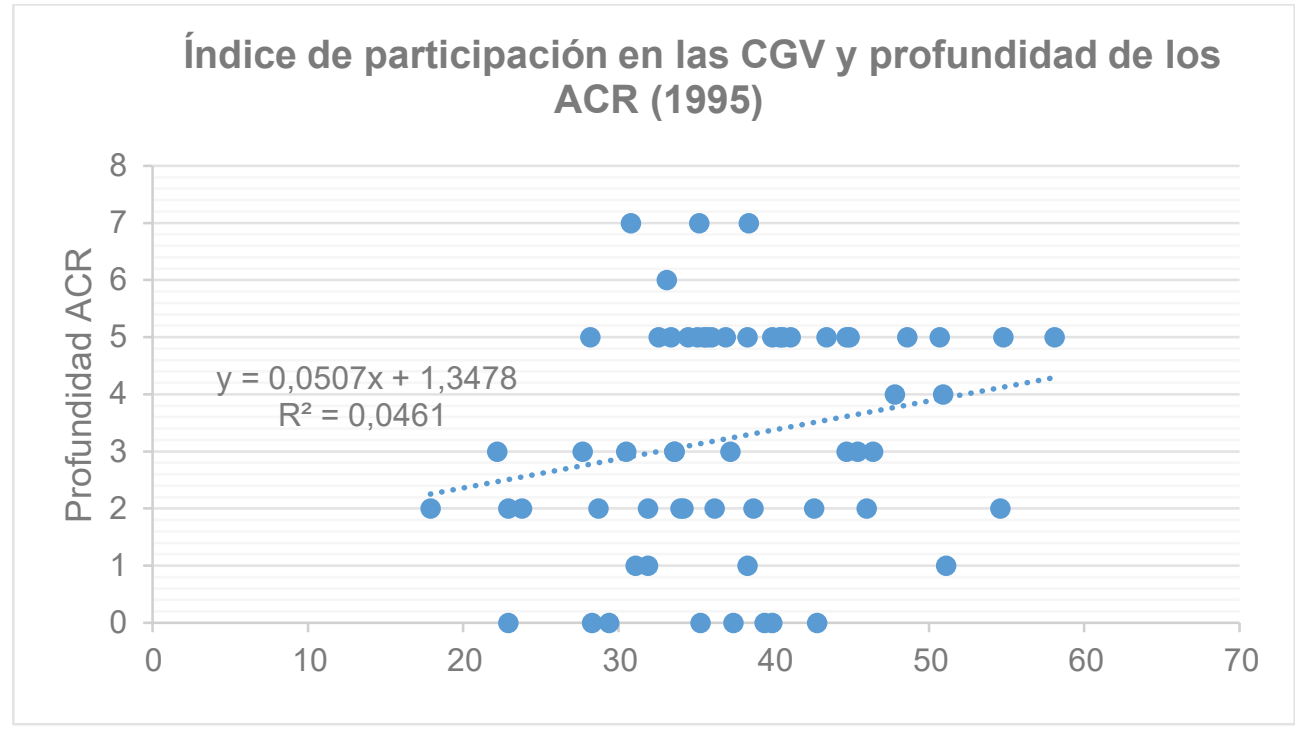

Figura 2. Evolución de la relación entre las CGV y la profundidad de los ACR.

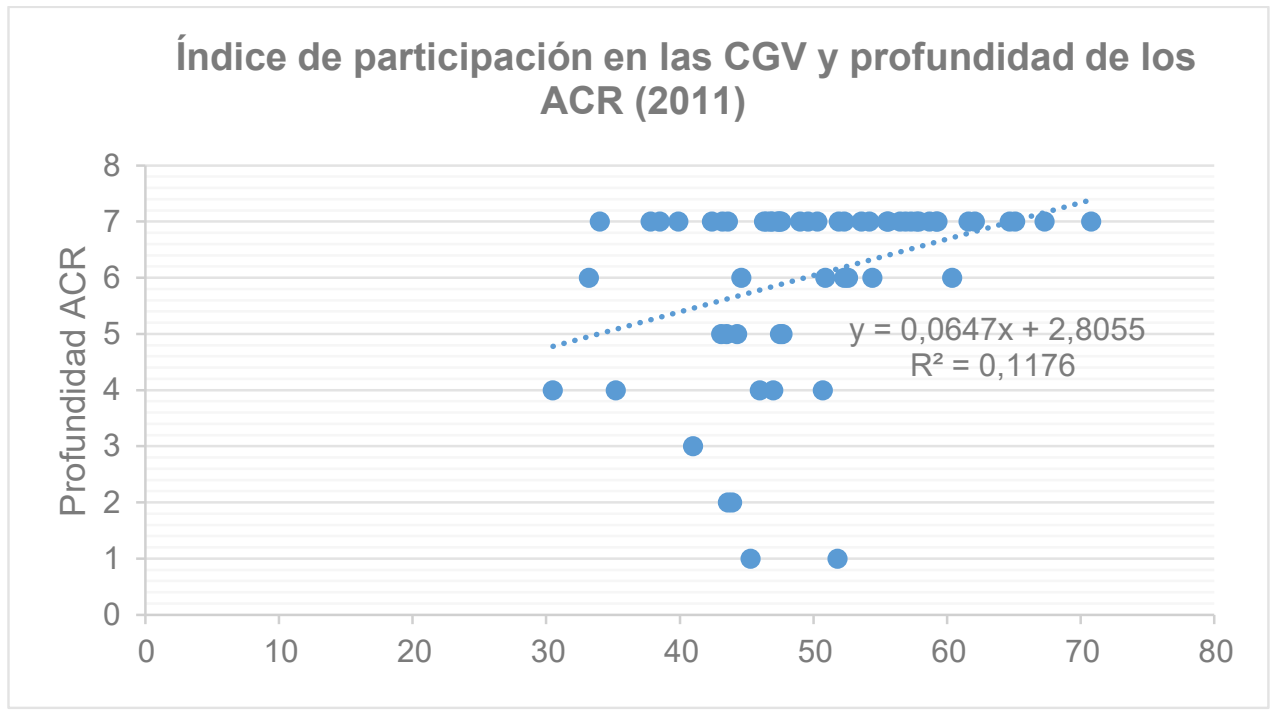

Figura 3. Evolución de la relación entre las CGV y la profundidad de los ACR. 
El período de análisis es uno de gran crecimiento del comercio mundial y, de manera específica, de intensificación de las CGV. Conforme a los datos de la OMC, entre 1995 y 2011 los países en desarrollo incrementaron en promedio en un $8 \%$ anual su participación en las CGV, mientras que los países desarrollados lo hicieron en un $13.1 \%$. Todos los países seleccionados en esta investigación han incrementado su participación en las CGV y prácticamente todos lo hicieron también en la firma de ACR profundos. Tal como se observa en las figuras 2 y 3 , la pendiente entre ambos fenómenos presenta una tendencia positiva, aunque la dispersión es elevada.

En primer lugar, en cuanto a las modalidades de los ACR, mientras que para 1995 la tendencia predominante era el establecimiento de ACR de grado cinco, en 2011 puede observarse un predominio de los acuerdos profundos, clasificados como de grado siete. En términos geográficos, donde más crece esta tendencia entre los dos años seleccionados es en la región del Pacífico, incluidos Japón y Corea, donde con anterioridad a 1995 no se había celebrado prácticamente ningún tipo de ACR sustantivos. En segundo lugar se observa un incremento en los países de Europa Oriental y, finalmente en algunos países de América Latina. Si bien los países europeos ascienden en la profundidad de sus compromisos, este incremento no reviste mayor impacto sobre el con- junto, debido a que para 1995 el nivel de integración alcanzado por la Unión Europea ya era sustantivo. Algo similar sucede con América del Norte, donde el Tratado de Libre Comercio de América del Norte (TLCAN, o bien NAFTA por sus siglas en inglés) había sido establecido en 1994.

En cuanto a la dinámica comercial, la expansión de la participación en las CGV no se produjo de manera homogénea, ni de igual forma en sus modalidades upstream y downstream. La participación regresiva creció un $17 \%$ promedio y un $28 \%$ la participación progresiva. Por ejemplo, Canadá pasó a tener un componente mayor de VA doméstico en exportaciones indirectas, al igual que Holanda o Nueva Zelanda, mientras que la República Checa creció más intensivamente en su participación hacia atrás. Típicamente se entiende que

si un país se ubica en la fase inicial de la cadena de producción (primeras etapas del proceso productivo), es probable que registre mayores valores de participación progresiva que de participación regresiva. Si un país se especializa en las últimas etapas del proceso productivo (fase avanzada de la cadena de producción), es probable que importe un gran número de bienes intermedios del extranjero y, por tanto, tenga un alto grado de participación regresiva. (OMC, 2014, p. 94)

$\overline{5}$ El comercio en las CGV creció más que el comercio mundial total. 
De tal forma que un crecimiento de la participación "hacia adelante" suele significar la incorporación de nuevas industrias en las instancias bajas de la cadena de valor (típicamente, los países exportadores de recursos energéticos, mineros y alimenticios). En cambio, un incremento en los niveles del VA extranjero en las exportaciones suele indicar un mayor involucramiento de la economía en el procesamiento de insumos, lo cual puede deberse tanto a un modelo tipo maquila o a la agregación de diseño.

No han sido los mismos países los que más han crecido en su participación en las CGV, los que han firmado los ACR más profundos, ni los que han variado más significativamente sus niveles de compromisos en materia de integración. De hecho, cuando se la examina estadísticamente, la vinculación entre estos dos fenómenos es débil. Si bien podemos observar que existe una relación de dependencia entre las dos variables ${ }^{6}$, el coeficiente de correlación es bajo ${ }^{7}$. Ello significa que si bien ambos fenómenos se vinculan, el conjunto observado tiene una distribución dispersa. Como puede verse en los gráficos, en muy bajo grado las CGV en 1995 guardaban relación con el tipo de compromisos asumidos por cada país en materia de integración. En 2011 la correlación entre los ACR y las CGV se incrementó, aunque continuó siendo baja.

Algunas variaciones se observan si se distingue entre los distintos tipos de participación en las CGV (figuras 4 y 5). $\mathrm{Si}$ se considera la participación hacia atrás o hacia adelante en las CGV de manera separada, se pueden apreciar patrones de ajuste más consistentes. Por ejemplo, aquellos países cuyas exportaciones totales tienen al menos un $30 \%$ de VA extranjero, han tendido a firmar acuerdos de integración que contemplan al menos seis de las condiciones estipuladas en el índice de profundidad. Esta correlación entre CGV y ACR, que es consistente con los análisis de Baldwin, se comprueba en la mayoría de los países de la región asiática (Tailandia, Malasia, Corea, Singapur, Taiwán) y en casos como Bulgaria, Irlanda, República Checa, Eslovaquia, Hungría y Luxemburgo. Sin embargo, por debajo de ese umbral de VA extranjero en las exportaciones, las conductas de los países se dispersan. Por otra parte, existen países con bajos niveles de VA extranjero o de VA doméstico, o de ambos, que a pesar de ese lugar en las CGV han firmado ACR profundos, como Colombia, por ejemplo.

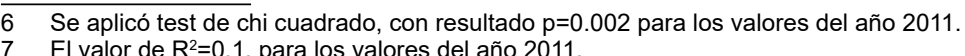




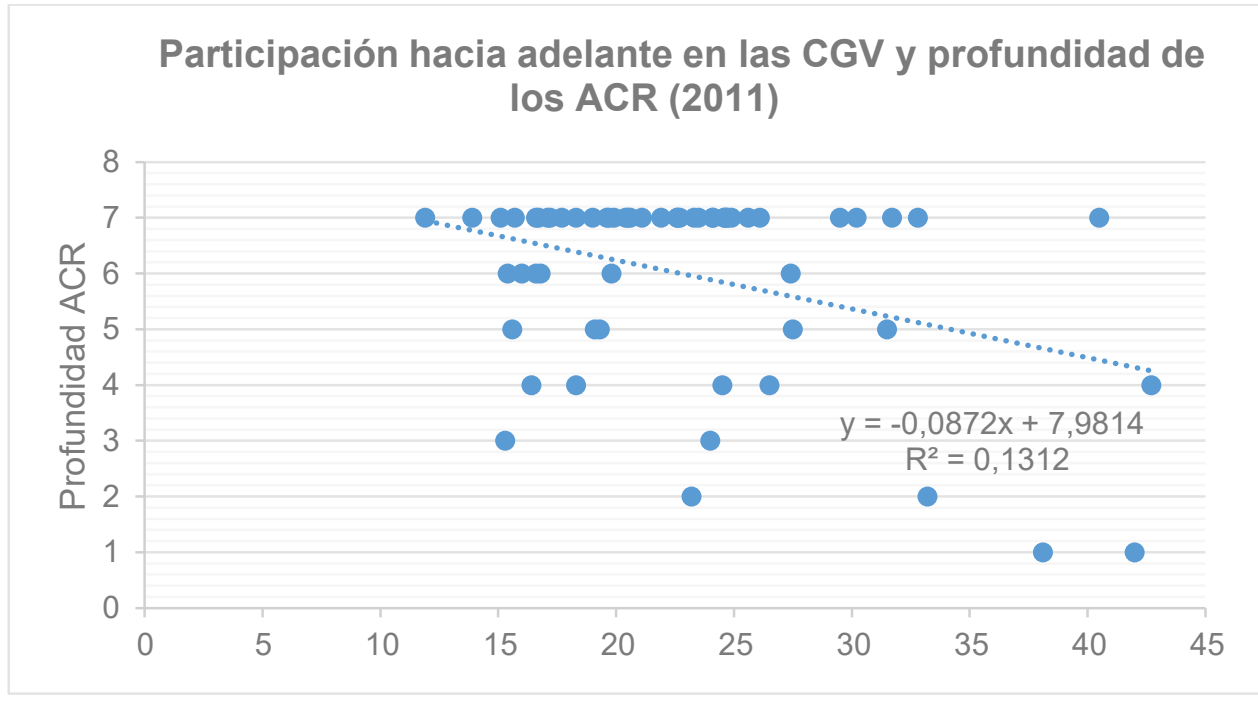

Figura 4. Profundidad de los ACR según tipo de participación en las CGV.

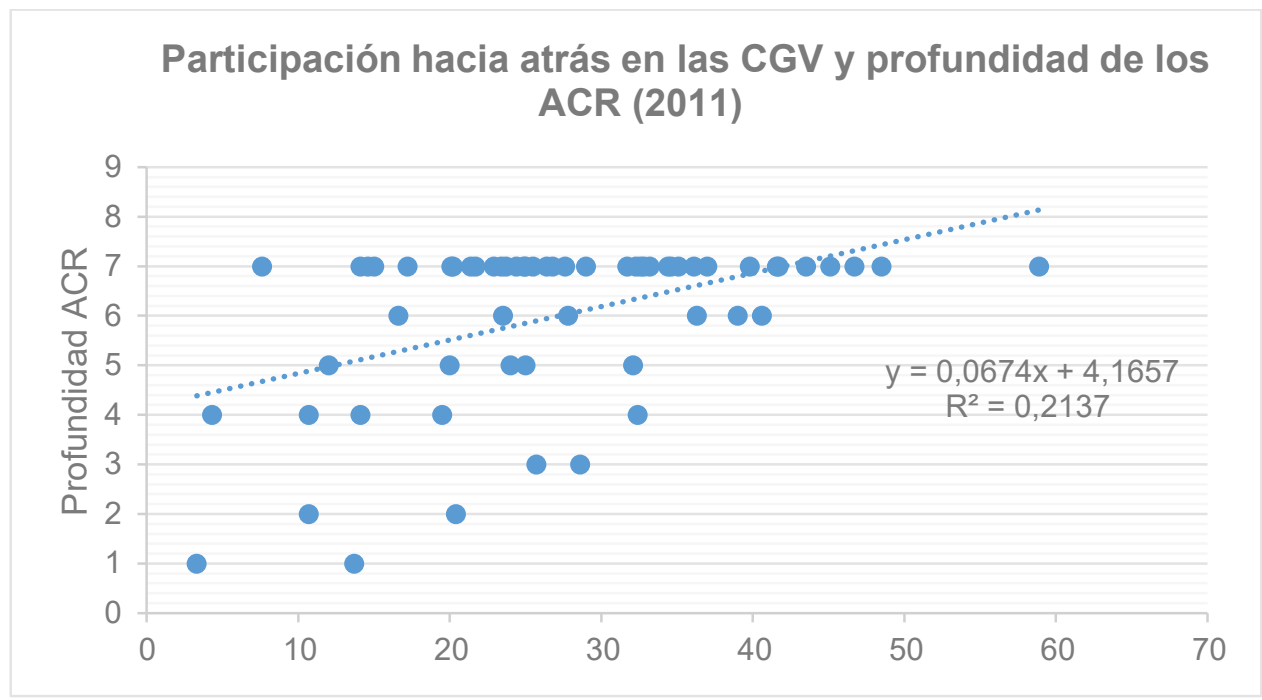

Figura 5. Profundidad de los ACR según tipo de participación en las CGV. 
Estas variaciones en los casos estudiados nos permiten afirmar que no en todas las economías la participación en CGV es necesaria para la firma de ACR profundos. Por el contrario, se observan casos de ACR profundos sin participación sustantiva en las CGV, por lo cual no sería esta una condición necesaria para la adopción de reformas consistentes con el "regionalismo del siglo XXI". En este sentido, otras variables podrían explicar más satisfactoriamente la participación de los países en los ACR profundos.

Para la ponderación de la tesis de la suficiencia de las $\mathrm{CGV}$ en su relación con los ACR profundos, la evidencia es levemente más consistente. Observamos una relación positiva entre las variables, aunque la presencia de casos que se apartan de la tendencia no nos permite extender las conclusiones a toda la población estudiada. Por ejemplo, Rusia ha mantenido una elevada participación en las CGV, pero su participación en los $\mathrm{ACR}$ ha sido menor a la de quienes tienen un GVC Index equivalente. Lo cual, entonces, relativiza las conclusiones que podrían alcanzarse en materia de suficiencia.

\section{EL HETEROGÉNEO ESCENA- RIO LATINOAMERICANO}

En esta sección nos proponemos analizar las características del vínculo entre
ACR profundos y $\mathrm{CGV}$ para tres países latinoamericanos, Colombia, Chile y Brasil, buscando - a partir de la comparación - revelar los posibles mecanismos detrás de la heterogeneidad de este conjunto. Los primeros dos países han adoptado acuerdos profundos y orientado su política comercial externa hacia las $\mathrm{CGV}$, a pesar de presentar diferencias en el grado de integración que tienen hacia tales estructuras de producción y comercialización. Brasil, en cambio, ha tenido una variación positiva en su participación en CGV entre 1995 y 2011 (aunque acumula un GVC Index menor que los tres primeros), pero no adoptó políticas de integración profunda (Tabla 1). ¿Se relacionan estas variaciones en las CGV con las diferencias en los distintos posicionamientos que estos países han adoptado hacia los acuerdos de integración profunda? Siguiendo el razonamiento presentado en el apartado anterior, sostendremos que los distintos tipos de participación en las CGV no alcanzan a explicar de manera completa las variaciones en las políticas hacia tales acuerdos, y que variables político-ideológicas han representado un papel tanto o más importante que aquella a la hora de explicar la presencia o ausencia de reformas en el sentido planteado por el regionalismo del siglo XXI, en particular, en la firma de ACR profundos. 
Tabla 1. La relación entre CGV y ACR en los países latinoamericanos (2011)

\begin{tabular}{lccc}
\hline & Chile & Colombia & Brasil \\
\hline GVC Index & $51.9 \%$ & $37.9 \%$ & $35.2 \%$ \\
\hline Participación regresiva & $20.2 \%$ & $7.6 \%$ & $10.7 \%$ \\
\hline Participación progresiva & $31.7 \%$ & $30.2 \%$ & $24.5 \%$ \\
\hline Principales socios en las CGV & China / EE.UU. & EE.UU./ EE.UU. & China/ EE.UU. \\
\hline Profundidad ACR & 7 & 7 & 4 \\
\hline $\begin{array}{l}\text { Contraparte en el primer ACR } \\
\text { profundo }\end{array}$ & $\begin{array}{c}\text { EE.UU. (2003) } \\
\text { Corea (2003) }\end{array}$ & EE.UU. (2006) & MERCOSUR (1995) \\
\hline Modelo de desarrollo & Neoliberal & Neoliberal & Neodesarrollista \\
\hline $\begin{array}{l}\text { Estrategia de Inserción } \\
\text { Internacional }\end{array}$ & $\begin{array}{c}\text { Regionalismo } \\
\text { abierto - Apertura }\end{array}$ & $\begin{array}{c}\text { Regionalismo } \\
\text { abierto - Apertura }\end{array}$ & Autonomía \\
\hline
\end{tabular}

\section{Chile}

Chile ha sido uno de los primeros países de la región en adoptar y mantener una política comercial liberal, en el contexto de una política exterior de apertura que buscaba proactivamente la firma de ACR profundos. Inicialmente, en la década de los setenta, la vía privilegiada fue la de las reformas unilaterales, pero a partir de los noventa esta apertura se ha transformado en una "apertura negociada", apoyada en una extensa red de acuerdos de libre comercio bi y plurilaterales ${ }^{8}$.

Con la vuelta de la democracia y el consecuente proceso de reinserción internacional, Chile se definió "como un país mediano, no periférico, integrado al mundo y a la región, exitoso económicamente y estable desde el punto de vista político-institucional" (Colacrai \& Lorenzini, 2005, p. 47). En ese marco, los ACR profundos han resultado componentes inherentes al modelo de desarrollo chileno. En efecto, el llamado regionalismo abierto puede entenderse como un pilar de la política externa de Chile (Aranda \& Riquelme, 2011) y, en ese marco, los acuerdos del regionalismo del siglo XXI son solo su expresión más contemporánea.

La participación en las CGV también ha sido clave en tal modelo de inserción. Desde 1995 hasta 2011 el comercio en las CGV creció un $12.9 \%$ anual, pasando de $33.2 \%$ a $51.9 \%$ su GVC Index. La composición de sus exportaciones varió notoriamente: el VA doméstico de las exportaciones que se incorporan a las ventas al exterior de terceros mercados pasó de $19.9 \%$ a $31.7 \%$, y de $4.1 \%$ a $20.2 \%$ el VA extranjero de las exportaciones. Conforme a la OECD (2015), factores tales como el tamaño de la economía y la distancia a los principales centros de manufacturas resultan aspectos que deprimen tal participación. En cambio, los bajos aranceles y la apertura hacia la inversión extranjera

8 "Prioridades de la política exterior", página web del Ministerio de Relaciones Exteriores de Chile. Consultado el 24 de febrero de 2016 . 
han sido factores que explican por qué Chile tiene una participación más destacada en las CGV que otros países de América Latina. El menor componente relativo de participación hacia atrás es explicado, por su parte, por la concentración de las exportaciones chilenas en productos primarios e intermedios, que incorporan pocos insumos importados.

En cuanto al tipo de socios, la ubicación de Chile en las CGV expresa su compleja situación geográfica. En sus vínculos hacia adelante se aprecia una orientación próxima hacia la región del Pacífico; en sus vínculos hacia atrás, una hacia Latinoamérica. China es el socio más importante para Chile en las CGV. Alrededor del $30 \%$ del VA domésticos de las exportaciones chilenas tiene a China como destino (OECD, 2015). Chile exporta a través de las cadenas de valor hacia China, Corea y los Estados Unidos. Hacia atrás, Chile importa insumos para sus exportaciones de Estados Unidos, Brasil y Colombia.

Chile ha aplicado activamente políticas de promoción para incrementar y mejorar su participación en las CGV. De hecho, el progreso en las relaciones económicas y la cooperación internacional forman parte de uno de los cuatro objetivos fundamentales de la política exterior desde el regreso a la democracia.

Los primeros acuerdos de comercio firmados por Chile fueron regionales, pero luego socios de extrazona como Europa, Estados Unidos, Corea, China y Japón entraron en la agenda, a la par que crecían y se diversificaban los intercambios comerciales, y que estos mismos socios cobraban importancia en las CGV de Chile, como se señaló más arriba. Actualmente, Chile posee 26 acuerdos con 64 mercados, que abarcan el $86.3 \%$ del PBI global y cubren más del $90 \%$ de sus exportaciones - sin haberse incluido todavía en estas cifras el recientemente firmado Acuerdo Integral Comprensivo y Progresivo de la Alianza Transpacífica (CPTPP, por sus siglas en inglés) - .

El acuerdo con Estados Unidos, catalogado como de grado seis, fue un hito en la historia de las negociaciones internacionales de Chile. La etapa final de las negociaciones tuvo lugar entre 2000 y 2002, a propuesta del Gobierno chileno. Para este, la negociación con los Estados Unidos significó consolidar y profundizar su estrategia de economía abierta, competitiva y apoyada en el dinamismo de las exportaciones. El propósito fue alcanzar un acuerdo de libre comercio ambicioso, que fuese más allá de la OMC y que incluyese todos los aspectos de la relación económica bilateral, comercio de bienes, servicios e inversiones, algunas materias propias de la nueva economía como el comercio electrónico y el tratamiento moderno de los temas ambientales y laborales (DIRECON, 2009). Estados Unidos era al momento de la negociación uno de los principales socios comerciales del país y además el principal inversor externo, 
lo cual explica el interés entre el empresariado chileno y sus contrapartes norteamericanas en la celebración de este acuerdo.

Simultáneamente, Chile negoció un acuerdo con la Unión Europea, el cual incorporó además de la liberalización del comercio de bienes y de servicios, normas que regulan inversiones, compras públicas, propiedad intelectual y obstáculos técnicos al comercio, así como un capítulo de cooperación aduanera y facilitación del comercio (grado seis). Cabe señalar que al momento de la firma del acuerdo, Europa tenía una participación semejante a la de EE.UU. dentro de las CGV de Chile, pero para el año 2005 Europa ya la había superado9.

La otra piedra angular de las negociaciones comerciales externas de Chile fue su ingreso al Foro de Cooperación Económica Asia-Pacífico (APEC), el cual es considerado de gran importancia para la proyección externa y la firma de acuerdos comerciales en la región (DIRECON, 2009). De hecho, el primer acuerdo de integración profundo de grado siete fue firmado en 2003 con Corea. A este se sumaron luego Japón, en 2007, y Australia, en 2008. Se trata de regiones con las que el comercio exterior crece de manera acentuada, llegando incluso la región de APEC a desplazar a América del Sur a partir de 2005 como socio comercial de Chile en el marco de las CGV.

El acuerdo con Corea del Sur comenzó a negociarse en 1998 cuando Corea manifestó su interés por alcanzar un TLC con Chile, firmándose el acuerdo cinco años más tarde. De acuerdo con Matus, exdirector de Asuntos Económicos Multilaterales del DIRECON, "la causa principal [que motivó a Corea] fue su necesidad de iniciarse en el campo de las negociaciones comerciales bilaterales, y Chile era lo suficientemente pequeño para que una eventual equivocación no fuese demasiado cara" (DIRECON, 2009, p. 166). Para Chile, la novedad era la diferencia cultural y el idioma de la negociación - el inglés-. El resultado de este proceso fue un instrumento que incluía la desgravación arancelaria para el $97.2 \%$ del universo arancelario, además de un conjunto de medidas de regulación del comercio, inversión y propiedad intelectual (DIRECON, 2009). Al año siguiente, en 2004, comenzó a negociarse el acuerdo con Japón, y en 2007 el celebrado con Australia, a petición de aquel país ${ }^{10}$.

Además de las firmas de estos tratados, una política relevante hacia las CGV

9 Mientras que en el año 2000 el valor agregado contenido en las exportaciones de Chile que provenía de Europa era de 564.913 millones de dólares, y el de EE.UU., 523.154; para el 2005 había pasado a 1413.613 millones de dólares, y 1030.06 millones de dólares, respectivamente.

10 El tratado fue finalmente firmado en 2009. La cobertura del acuerdo fue total, sin sectores excluidos. Se contemplan además políticas en materia de inversión, propiedad intelectual y contiene un capítulo específico dedicado al comercio electrónico. Conforme al DIRECON, es "el primer acuerdo que incluye normas específicas relativas a la autentificación, derechos del consumidor, protección de datos personales y comercio sin papel" (DIRECON, 2009, p. 179). 
ha sido la de facilitación de comercio. Chile ha sido pionero en medidas de esta índole, siendo los costos y tiempos de exportación/importación inferiores al promedio mundial.

Considerando estos elementos, sostenemos que el caso Chile presenta un vínculo singular en la relación que este artículo se propone analizar. En el caso de este país, la apertura económica es previa al estallido de las CGV como fenómeno significativo del orden económico internacional. Es decir, no fue "el vacío entre las normas del siglo XX y el comercio del siglo XXI" el que dio lugar a los cambios en la política de comercio exterior e inversiones, sino que fue la historia de la tradicional política de apertura la que posibilitó la participación creciente del país en las CGV. Las CGV encontraron un buen soporte institucional y contribuyeron a acentuar una tendencia que era preexistente. En ese punto sí se detecta una sintonía entre CGV y ACR profundos, como en el caso del acuerdo Chile-Corea del Sur, pero antecedida de un contexto de políticas que ya mostraba signos de cambios. En la mayoría de los casos, la propuesta de negociación provino de la contraparte, siendo que el actor externo fue el que promovió la firma de los acuerdos profundos, en un contexto nacional proclive a hacerlo. La manera en la cual Chile en su política exterior ha definido su inserción en el mundo, junto con el modelo de desarrollo adoptado, son los dos prismas complementarios a través de los cuales debe entenderse la firma de los acuerdos profundos con socios como Corea, Japón o Australia. Las CGV tienen un lugar importante, que refuerza y retroalimenta la orientación de políticas aquí reseñada, pero la firma de acuerdos profundos solo puede entenderse si se consideran primero los efectos de variables como el modelo de desarrollo y la estrategia de inserción internacional.

\section{Colombia}

Tras la apertura realizada en los años 90, Colombia inició en el siglo XXI una nueva etapa de liberalización, estableciendo en el Plan Nacional de Desarrollo la promoción de las exportaciones y de la inversión extranjera como uno de los pilares del desarrollo económico. Fue así como

para fomentar las exportaciones y la inversión, Colombia se propuso internacionalizar su economía al mundo globalizado. Esto se conseguiría a través de varios instrumentos, siendo el primero la firma de tratados de libre comercio (TLC) que crearían zonas de libre comercio que brindarían condiciones competitivas de acceso a nuevos mercados. (Solano, 2013, p. 16)

En consecuencia, en 2006 se firmó un TLC profundo con Estados Unidos, en 2008 con EFTA, en 2012 con Perú y la Comunidad Europea, y en 2013 con Corea del Sur. Tanto la participación en las CGV como la profundidad de los 
ACR se incrementaron en el período de estudio.

En materia de las CGV, la situación de Colombia es particular entre los países latinoamericanos, puesto que su GVC Index, según el cual el $37.9 \%$ de las exportaciones se integra en los eslabonamientos globales de producción, se distribuye de una manera muy despareja. El $80 \%$ de sus exportaciones en CGV se explica por su participación hacia adelante, y solo el $20 \%$ lo hace en los eslabonamientos "hacia atrás". Según Ramírez (2011),

en los últimos siete años [entre 2004 y 2011] han crecido el comercio exterior de Colombia y la inversión extranjera en el país. Pero ese crecimiento se debe, en gran parte, al sector extractivo, minero-energético, y no a una inversión externa directa en un sector productivo capaz de mejorar la competitividad del país y de incentivar la transferencia de tecnología. En consecuencia, las exportaciones han seguido siendo de bajo VA y se concentran en pocos productos y reducidos destinos. (p. 94)

Los principales socios son, como proveedores de insumos, Estados Unidos, China y México; y como mercados para las exportaciones de los insumos colombianos a través de las CGV, Estados Unidos, Chile y China. En ambos casos la participación de Estados Unidos supera ampliamente a los segundos y terceros sumados.
En materia de acuerdos comerciales, el tratado más importante firmado por Colombia fue el de Estados Unidos, en 2006. Según el Gobierno colombiano, tres razones motivaron esa decisión: la primera, consolidar las preferencias otorgadas en la Ley de Promoción Comercial Andina y de Erradicación de Drogas (ATPDEA); la segunda, generar ventajas frente a otros competidores en el ámbito internacional; tercero, ganar competitividad y conquistar nuevos mercados (Sistema de Información sobre Comercio Exterior [SICE], s.f.). Asimismo, la existencia de importantes redes de negocios entre ambos países ha sido señalada como uno de los determinantes de este acuerdo (Pardo, 2012). Aunque, según Ramírez (2011), este y los demás tratados de libre comercio también han estado fundamentados por la necesidad de Colombia de reinsertarse en el sistema internacional a partir de una agenda más amplia que la exclusivamente de seguridad y terrorismo.

Debe notarse que la relevancia del vínculo con los Estados Unidos es previa a la firma del Acuerdo de Libre Comercio, concentrando una gran intensificación del comercio, en términos relativos, en el período 2000 a 2005.

Con los socios regionales (México y Chile de la Alianza del Pacífico) y con Corea - casos en los que también existen TLC profundos - las vinculaciones en el marco de las CGV son relevantes. El VA originario de estas regiones contenido en las exportaciones de Colombia 
pasó en el período entre 2005 y 2011 de 165.262 millones de dólares a 272.010 millones en el primer caso, y 46.687 millones de dólares a 65.969 millones. Por su parte,

aproximadamente el 65 por ciento de la inversión extranjera recibida en Colombia proviene de países con los cuales Colombia tiene o ha iniciado negociaciones de un acuerdo de inversión y a su vez, el 66 por ciento de la inversión colombiana en el exterior tiene como destino países con los cuales se tiene suscrito o se está negociando un acuerdo de inversión. (OMC, 2012, p. 13)

La búsqueda de atracción de inversiones, de hecho, es identificada como uno de los principales objetivos en el acuerdo de la Asociación Europea del Libre Comercio (EFTA). En el caso del acuerdo con Corea debe señalarse también el interés del Gobierno de Colombia por acercarse a Asia y, en particular, por ingresar al foro de APEC. Ello se inscribe dentro de una política comercial externa que busca la diversificación de los vínculos.

En el caso colombiano, la firma de ACR profundos es tanto el resultado de la búsqueda de una determinada inserción internacional, como de la aplicación de políticas económicas y comerciales de apertura. Si bien las redes de negocios han tenido una participación importante, especialmente en el acuerdo con los EE.UU., este acuerdo no puede comprenderse solamente a partir de la participación de Colombia en las CGV. En los casos de los ACR profundos posteriores, indicamos que una vez que la participación en las CGV fue incluida en los objetivos de gobierno y jerarquizada, ello permitió ampliar el conjunto de instrumentos disponibles y favoreció la celebración de estos acuerdos propios del llamado "regionalismo del siglo XXI".

\section{Brasil}

El perfil de participación actual de Brasil en las CGV es parecido al de Colombia. Existe un marcado predominio del VA doméstico por sobre el VA extranjero. El componente principal es, en este caso, el VA en materia de servicios, sector económico que explica el $44.2 \%$ del VA doméstico contenido en las exportaciones. El GVC Index es de $35.2 \%$ sobre el total de las exportaciones, ubicándose en orden de jerarquía por debajo de los otros países ya analizados. Sin embargo, a diferencia de Colombia, en Brasil no se han firmado ACR profundos.

Los principales socios de Brasil como proveedores de insumos extranjeros en las CGV y como exportadores de los productos intermedios brasileños son Estados Unidos, China y Alemania. Para Saavedra y Sardelli (2013), la inserción de este país en las CGV muestra el carácter periférico o marginal de la inserción económica de Brasil. Tanto el 
perfil de su dotación de recursos naturales, como

el sistema tributario que castiga el valor añadido, los cuellos de botella en la infraestructura y la baja capacidad de innovación, sirven para explicar esta posición, pero también hay que destacar aquellos que limitan la conectividad de Brasil a la economía internacional, es decir, algunos aspectos relacionados con la agenda comercial y de inversiones. (Saavedra \& Sardelli, 2013, p. 14)

La política comercial externa de Brasil, y su posición respecto a los ACR profundos, debe enmarcarse dentro del contexto del MERCOSUR, principal proceso de integración en el que está involucrado este país desde 1991, y que condiciona las políticas comerciales que Brasil puede aplicar con relación a su arancel y algunas otras medidas consolidadas en el bloque regional. Asimismo debe tener en cuenta el hecho de que, conforme a Motta (2003), conservar un margen de maniobra para el desarrollo de un "neoactivismo" en política comercial — término del citado autor-, fue una constante de los gobiernos brasileros frente a las crisis externas desde 1995. Esta percepción se acentuó con la llegada del Gobierno de Lula. En su política exterior reciente, Brasil privilegió a la región de América del Sur tanto en lo económico-comercial como en lo político-diplomático. Aumentó la resistencia a negociar acuerdos con los países desarrollados como los Estados Unidos y la Unión Europea, se incre- mentó el peso asignado a la OMC como foro para las negociaciones comerciales, y se rechazó la inclusión en la agenda multilateral de cuestiones como inversiones y compras públicas (Motta \& Polonia, 2011).

En cuanto a los compromisos en materia de ACR, conforme a Dür et al. (2014), el MERCOSUR es un acuerdo de grado cuatro en términos de su profundidad. Si se consideran los protocolos anexos, el bloque tiene una cobertura amplia, aunque de bajo cumplimiento (Sistema Económico Latinoamericano [SELA], 2014). Esta situación se complementa con una agenda externa que ha avanzado más en términos políticos que económicos. A partir del año 2000, mientras que otros países celebraban acuerdos de integración del "regionalismo del siglo XXI", Brasil promovía en el MERCOSUR la firma de acuerdos sur-sur, poco profundos. En ese conjunto pueden mencionarse la renegociación del patrimonio histórico con la ALADI, las negociaciones con India y con la Southern African Customs Union (SACU), así como con Egipto. También la promoción de una nueva ronda del Sistema Global de Preferencias Comerciales entre Países en Desarrollo (SGPC). En su conjunto, las negociaciones externas de MERCOSUR se han concentrado en el tratamiento de las preferenciales en el plano arancelario, y no se han generado estrategias de negociación en relación con los llamados "nuevos temas" o temas "OMC-Plus" u "OMC-x", salvo cuando estos fueron demandados por 
la contraparte (como en el caso de la negociación entre el bloque y la Unión Europea).

En cuanto a otros componentes de la política comercial externa, hay que destacar que tanto los costos de importación como de exportación son mayores en Brasil que en el promedio del mundo. No obstante, Brasil ratificó en el primer trimestre de 2016 el Acuerdo de Facilitación del Comercio de la OMC, y viene realizando una adecuación de políticas de esa índole, promovida por la Cámara de Comercio Exterior (CAMEX).

A modo de síntesis, señalamos que el caso brasileño, caracterizado como de "participación media-baja en las CGV" y de "ausencia de ACR profundos", es consistente con la correlación de variables propuesta en el marco conceptual. Entre uno y otro elemento deben tomarse en consideración los aspectos políticos que moldean la política comercial externa brasilera, la cual se encuentra atravesada por los objetivos del desarrollo y la autonomía. Así, durante la última década ha resultado más relevante para este país el comercio sur-sur, impulsado por el modelo neodesarrollista y una inserción autonomista, que la participación en las CGV a la hora de formular su política comercial externa y celebrar acuerdos comerciales.

\section{CONCLUSIONES}

La vinculación entre CGV y ACR profundos se erige como un vínculo complejo. La correlación entre las variaciones de uno y otro fenómeno obtenida en nuestro estudio ha sido menor que la esperada conforme al razonamiento teórico predominante en la disciplina. Asimismo, observamos que una elevada participación en las CGV puede resultar una condición suficiente para la firma de ACR profundos, pero no resulta una condición necesaria para estos. Asimismo, notamos algunos casos con participación en las CGV pero ACR de nivel medio. Estas observaciones motivan la realización de análisis más exhaustivos acerca del vínculo en cuestión.

En el caso de los países latinoamericanos, la participación en las CGV ha sido posterior a la implementación de reformas internas de sus economías. Y esta participación no siempre derivó en ACR profundos. El estudio de los procesos de negociación de los tratados firmados por los países latinoamericanos muestra que, siendo su participación en la CGV media o baja, el argumento según el cual los países adherirían al "regionalismo del siglo XXI" buscando satisfacer necesidades de "hacer negocios afuera" y "conectar las fábricas" no resulta suficiente para entender los procesos sucedidos. La adhesión a los ACR profundos, en los países que se produjo, no contó con una participación elevada en las CGV; esta no fue necesaria. La firma de ACR profundos fue una decisión que excedió la dimensión económica, puesto que las variables políticas tuvieron un peso importante. Ello ha sido un elemento que explica las conductas 
tanto a favor como en contra de la firma de los ACR profundos, y que permite comprender las variaciones observadas entre los casos. En tal sentido, los hallazgos de esta investigación robustecen los argumentos que ponen de relieve las motivaciones políticas gubernamentales antes que los intereses económicos empresariales como factor explicativo de la firma de ACR profundos.

En los países en los que se produjo una adhesión a los ACR profundos se observa la implementación de políticas económicas de corte liberal, y de estrategias de inserción internacional aperturistas, próximas al regionalismo abierto. En estos países se constata además que se sucedieron reformas unilaterales en materia de facilitación de negocios y de mejora del entorno de negocios a la par de los acuerdos comerciales. Asimismo se observa como constante, en los dos casos que sí se firmaron estos acuerdos, una participación relevante de los Estados Unidos en los flujos comerciales y de inversiones. En ese sentido sí puede haber existido una "demanda" local, con vínculos con los Estados Unidos, que promovió el establecimiento de ACR profundos - lo que sería consistente con investigaciones como la de Osgood (2018) — , pero estos solo tuvieron lugar en función de un acompañamiento político y de su coherencia con el modelo de desarrollo y estrategia de inserción de cada caso analizado. 


\section{REFERENCIAS}

Actis, E., Lorenzini, M.E. \& Zelicovich, J. (2016). Política exterior argentina en debate: una interpretación desde la vinculación del modelo de desarrollo y la estrategia de inserción internacional (1983-2011). En A. Busso (comp.), Modelos de desarrollo e inserción internacional. Aportes para el análisis de la política exterior argentina desde la redemocratización (1983-2011). (pp. 9-26). Rosario, Argentina: UNR Editora.

Antrás, P. \& Staiger, R. (2012). Offshoring and the Role of Trade Agreements. American Economic Review, 102(7), 3140-83.

Aranda, G. \& Riquelme, J. (2011). La política exterior de Chile desde 1990. Inserción internacional y prioridad regional. Cuadernos sobre Relaciones Internacionales, Regionalismo y Desarrollo, (10), 11-41.

Baldwin, R. (2011). 21st Century Regionalism: Filling the Gap between 21st Century Trade and 20th Century Trade Rules. World Trade Organization (WTO), Economic Research and Statistics Division. No. ERSD-2011-08. Retrieved from https://www.wto.org/english/res_e/reser_e/ersd201108_e.pdf

Baldwin, R. (2012). WTO 2.0: Global Governance of Supply Chain Trade. CEPR, Policy Insight, (64), 1-24.

Basave, J. (2007). Elementos a considerar para una agenda de investigación económica en América Latina. En A. Girón \& E. Correa (coord.), Del sur hacia el norte: economía politica del orden económico internacional emergente. (pp. 201-216). Buenos Aires: CLACSO.

Bathia, U.S. (2013). The Globalization of Supply Chains-Policy Challenges for Developing Countries. In D. Elms \& P. Low (eds.). Global Value Chains in a Changing World. (pp. 313-328). Ginebra: Fung Global Institute (FGI), Nanyang Technological University (NTU), and World Trade Organization (WTO).

Bianchi, C. \& Szpak, E. (2015). Cadenas globales de valor, comercio internacional y actuación empresaria. Revista Argentina de Investigación en Negocios, 1(1), 11-27. 
Blanchard, E., Bown, C. \& Johnson, R. (2016). Global Supply Chains and Trade Policy. World Bank Group. Policy Research Working Paper $n .^{\circ}$ 7536. Retrieved from http://www-wds.worldbank.org/external/default/WDSContentServer/ WDSP/IB/2016/01/19/090224b0840c0fd4/1_0/Rendered/PDF/Global0supply0chains0and0trade0policy.pdf

Breuning, M. (2007). Foreign Policy Analysis: A Comparative Introduction. Nueva York: Palgrave MacMillan.

Colacrai, M. \& Lorenzini, M.E. (2005). Política exterior de Chile: ¿Excepcionalidad o continuidad? Una lectura combinada de "fuerzas profundas" y tendencias". confines de Relaciones Internacionales y Ciencia Política, 1(2), 45-63.

Dalle, D., Fossati, V. \& Lavopa, F. (2013). Política industrial: ¿el eslabón perdido en el debate de las Cadenas Globales de Valor? Revista Argentina de Economía Internacional, 2, 3-16.

DIRECON. (2009). Chile. 20 años de negociaciones comerciales. Santiago: Ministerio de Relaciones Exteriores de Chile, B\&B Impresores.

Dür, A., Baccini, L. \& Elsig, M. (2014). The Design of International Trade Agreements: Introducing a New Dataset. The Review of International Organizations, 9(3), 353-375.

Durán, J.E. \& Zaclicever, D. (2013). América Latina y el Caribe en las cadenas internacionales de valor. CEPAL, Serie Comercio Internacional, N. 124. Recuperado de http://repositorio.cepal.org/bitstream/handle/11362/35879/ LCL3767.pdf?sequence $=1$

Fernández, V.R. \& Trevignani, M.F. (2015). Cadenas globales de valor y desarrollo: perspectivas críticas desde el sur global. Dados, 58(2), 499-536. Recuperado de http://www.scielo. br/scielo.php?script=sci_arttext\&pid=S0011 $-52582015000200499 \& \operatorname{lng}=\mathrm{en} \& \mathrm{nrm}=\mathrm{iso}$.

Gereffi, G. (2001). Las cadenas productivas como marco analítico para la globalización. Problemas del Desarrollo, 32(125), 9-38.

Gereffi, G., Humphrey, J., Kaplinsky, R. \& Sturgeon, T. (2001). Introduction: Globalisation, Value Chains and Development. IDS Bulletin, 32(3), 1-8. 
Gilpin, R. (2001). Global Political Economy. Understanding the International Economic Order. Princeton: Princeton University Press.

Hermann, M G. (2001). How Decision Units Shape Foreign Policy: A Theoretical Framework. International Studies Review, 3(2), 47-81.

Hoekman, B. \& Kostecki, M. (2009). The Political Economy of the World Trade System. New York: Oxford University Press.

Hopkins, T. \& Wallerstein, I. (1977). Patterns of Development of the Modern World-System. Review, 1(2), 111-145.

Lasagna, M. (1995). Las determinantes internas de la política exterior: un tema descuidado en la teoría de la política exterior. Estudios Internacionales, 28(111), 387-409.

Laget, E., Osnago, A., Rocha, N. \& Ruta, M. (2018). Deep Trade Agreements and GlobalValue Chains. World Bank Group, Policy Research Working Paper $\mathrm{n}^{\circ}$ 8491.

López, J. (2012). The Impact of Free Trade Agreements on Vertical Specialization. Swiss National Centre of Competence in Research, Working Paper n²012/36.

Mansfield, E. \& Milner, H. (1999). The new wave of Regionalism. International Organization, 53(3), 589-627.

Moravcsik, A. (1997). Taking Preferences Seriously: A Liberal Theory of International Politics. International Organization, 51(4), 513-553.

Motta, P. (2003). Brasil: retos de la política industrial y comercial de principios del siglo XXI. Información Comercial Española ICE Revista de Economía, (810), 127-136.

Motta, P. \& Polonia, S. (2011, abr.-mayo). Política econômica externa do governo Dilma: dilemas e desafios. Pontes, 7(1). Recuperado de http://www.ictsd.org/ downloads/pontes/pontes7-1.pdf

Nicita, A., Ognivtsev, V. \& Shirotori, M. (2013). Global Supply Chains: Trade and Economic Policies for Developing Countries. United Nations Conference on 
Trade and Development. Policy Issues in International Trade and Commodities Study Series No. 55. Retrieved from http://unctad.org/en/PublicationsLibrary/ itcdtab56_en.pdf

OECD. (2015). Diagnostic of Chile's Engagement in Global Value Chains. Retrieved from https://www.direcon.gob.cl/wp-content/uploads/2015/12/diagnostic-chile-gvc-2015.pdf

Orefice, G. \& Rocha, N. (2011). Deep Integration and Production Networks: An Empirical Analysis. WTO Economic Research and Statistics Division. Staff Working Paper ERSD-2011-11. Retrieved from https://www.wto.org/english/ res_e/reser_e/ersd201111_e.pdf

Organización Mundial del Comercio -OMC-. (2011). Informe sobre el comercio mundial 2011. Ginebra: WTO Press.

Organización Mundial del Comercio -OMC-. (2012). Examen de las políticas comerciales. Informe de Colombia. Recuperado de https://www.wto.org/spanish/ tratop_s/tpr_s/tp365_s.htm

Organización Mundial del Comercio -OMC-. (2014). Informe sobre el comercio mundial 2014. Ginebra: WTO Press.

Osgood, I. (2018). Globalizing the Supply Chain: Firm and Industrial Support for the US Trade Agreements. International Organization, 72(2), 1-30.

Pardo, M. (2012). El Tratado de Libre Comercio Colombia-Estados Unidos: resultados y perspectivas. Puentes, 13(3). Recuperado de http://www.ictsd.org/bridges-news/puentes/news/el-tratado-de-libre-comercio-colombia-estados-unidos -resultados-y

Prochnik, V. (2010). La inserción de América Latina en las Cadenas Globales de Valor. Montevideo: Red Mercosur.

Ramírez, S. (2011, ene.-feb.). El giro de la política exterior colombiana. Revista Nueva Sociedad, (231), 79-95.

Rodrik, D. (2018). New Technologies, Global Value Chains, and Developing Economies. NBER Working Paper, $\mathrm{n}^{\circ} 25164$. 
Ruta, M. (2017). Preferential Trade Agreements and Global Value Chains. Theory, Evidence and Open Questions. The World Bank, Policy Research Working Paper $\mathrm{n}^{\circ} 8190$.

Saavedra, S. \& Sardelli, F. (2013). Cadenas globales y políticas para una mayor integración internacional de Brasil. Puentes, 14(6). Recuperado de http://www. ictsd.org/bridges-news/puentes/news/cadenas-globales-y-pol\%C3\%ADticas-para-una-mayor-integraci\% $\mathrm{C} 3 \% \mathrm{~B} 3 n$-internacional-de

Sistema de Información sobre Comercio Exterior -SICE-. (s.f.). Tratado de Libre Comercio Colombia-Estados Unidos. Resumen. Organización de Estados de las Américas. Recuperado de http://www.sice.oas.org/TPD/AND_USA/Studies/COLResumen_s.pdf

Sistema Económico Latinoamericano-SELA. (2014). Evolución del Mercado Común del Sur (MERCOSUR). En Informe presentado en XL Reunión Ordinaria del Consejo Latinoamericano, Caracas, Venezuela. 26 al 28 de noviembre de 2014. SP/CL/XL.O/Di No 8-14. Recuperado de http://www.sela.org/media/264703/ t023600006230-0-di_8_evolucion_mercosur.pdf

Solano, C. (2013). La política comercial de Colombia: del pasado al futuro. Puentes, 14(5). Recuperado de http://www.ictsd.org/bridges-news/puentes/news/ la-pol\%C3\%ADtica-comercial-de-colombia-del-pasado-al-futuro

Strange, S. (1996). The Retreat of the State: The Diffusion of Power in the World Economy. Cambridge: Cambridge University Press. 